\title{
Avances y desafíos en la formación universitaria de docentes en Educación Bilingüe Intercultural
}

\author{
Advances and Challenges in University Teacher \\ Instruction in Intercultural Bilingual Education \\ Avanços e desafios na formação universitária de \\ docentes em Educação Bilíngue Intercultural
}

Tunte amuley ka chem petu nentugeafuy kimeltun mew ta pu

kimeltuchegealu Educación Bilingüe Intercultural mew

José Enrique Cortez $\mathrm{Sic}^{1}$

Universidad de San Carlos de Guatemala, Guatemala Grupo de Investigación Formación de Profesores de EFPEM Grupo de investigación HISULA - UPTC

Recepción: 15/04/2019

Evaluación: 15/05/2019

Aceptación: 23/05/2019

Artículo de Investigación - Revisión

DOI: https://doi.org/10.19053/01227238.10001

\section{RESUMEN}

El presente trabajo desarrolla un proceso de análisis y reflexión en torno a la formación universitaria de docentes en el ámbito de la Educación Bilingüe Intercultural (EBI), proceso que se lleva a cabo en la Universidad de San Carlos de Guatemala a través de la Escuela de Formación de Profesores de Enseñanza Media (EFPEM), unidad académica que, a partir del año 2002, ha tomado esta responsabilidad como una respuesta a las necesidades de preparación del recurso humano en esta modalidad en el sistema educativo guate- malteco y en su sociedad, en el marco de una educación con pertinencia cultural, étnica y lingüística; esta iniciativa, originada a través de alianzas estratégicas con instituciones nacionales e internacionales, ha tenido un avance significativo en la formulación e implementación de carreras a niveles de pregrado y posgrado. La metodología utilizada se fundamentó en obtener información a través de fuentes primarias, la diligencia de un cuestionario y entrevistas a estudiantes de las carreras de profesorado, licenciatura y maestría en

$1 \quad$ Profesor Titular IV de la Escuela de Formación de Profesores de Enseñanza Media (EFPEM) de la Universidad de San Carlos de Guatemala (USAC) con grado de maestría en Educación Bilingüe Intercultural, integrante del Grupo de Investigación Formación de profesores de EFPEM y del grupo HISULA - UPTC, miembro del Consejo Directivo de la EFPEM como representante de docentes. Perteneciente al grupo étnico Maya-Achí. Correo electrónico: encorsi@gmail.com 
EBI, así como egresados, docentes y autoridades de la EFPEM como sujetos con conocimientos y experiencias académicas y del contexto sociocultural de Guatemala.

El estudio parte desde el inicio de la formación docente en EBI, el cual data del 2002 a la fecha; en este tiempo transcurrido son evidentes los avances en la formulación de carreras que promueven una educación altamente pertinente, requerida en el ámbito nacional, dadas las necesidades educativas existentes en Guatemala, como un país pluricultural, multiétnico y multilingüe. Los desafíos en esta materia van desde el mejoramiento de la formación docente para contextos de diversidad cultural, el rediseño curricular que incluya los conocimientos, saberes y tecnología ancestrales, la profundización de la cosmovisión de los pueblos indígenas, la práctica de una verdadera interculturalidad desde la educación superior, el fortalecimiento del idioma materno, entre otros, para proveer a los futuros profesionales una formación sólida, incluyente y contextualizada.

Palabras clave: educación bilingüe intercultural; formación docente; educación intercultural; Historia de la educación latinoamericana; educación superior.

\section{ABSTRACT}

This work constitutes an analysis and reflection on the university teacher instruction in the field of Intercultural Bilingual Education (IBE). This process is carried out at The University of San Carlos in Guatemala through the Escuela de Formación de Profesores de Enseñanza Media (EFPEM), an academic unit which, since 2002 , has taken on this responsibility as a response to the training needs in this modality in the Guatemalan education and social system, within the framework of an education with cultural, ethnic and linguistic relevance. This initiative, originated through strategic alliances with national and international institutions, has made significant progress in the design and implementation of undergraduate and graduate programs. The methodology was based on information obtained from primary sources, a questionnaire, and interviews with students from the teacher instruction bachelor, and from the master in IBE, as well as with EFPEM graduates, teachers, and authorities; all of them, individuals with academic knowledge who have experienced the socio-cultural context of Guatemala. This study covers the period from the beginning of the university teacher instruction in IBE program to date. During this time, progress has been made in the design of careers that promote a highly relevant education, capable of satisfying at the national level, the needs of a multicultural, multiethnic and multilingual country such as Guatemala.

Keywords: intercultural bilingual education; teacher instruction; intercultural education; History of Latin American education; higher education.

\section{RESUMO}

O presente trabalho desenvolve um processo de análise e reflexão em torno à formação universitária de docentes no âmbito da Educação Bilíngue Intercultural (EBI), processo que se leva a cabo na Universidade de São Carlos da Guatemala através da Escola de Formação de Professores de Ensino Médio (EFPEM), unidade acadêmica que, a partir do ano
2002, vem levando esta responsabilidade como uma resposta às necessidades de preparação do recurso humano nesta modalidade no sistema educativo guatemalteco e na sua sociedade, no quadro de uma educação com pertinência cultural, étnica e linguística; esta iniciativa, originada através de alianzas estratégicas com instituições nacionais e internacionais, 
tem tido um avanço significativo na formulação e implementação de carreiras em modalidade de licenciatura e mestrado. A metodologia utilizada fundamenta-se em obter informação através de fontes primárias, a diligência de um questionário e entrevistas a estudantes das carreiras de profesorado, licenciatura e mestrado em EBI, assim como ex-alunos, docentes e autoridades da EFPEM como sujeitos com conhecimento e experiências acadêmicas e do contexto sociocultural da Guatemala. O estudo parte desde o início da formação docente em EBI, no qual vem desde 2002 até esta data; neste tempo transcorrido são evidentes os avanços na formulação de carreiras que promovem uma educação altamente pertinente, requerida no âmbito nacional, dadas as necessida- des educativas existentes na Guatemala, como um país pluricultural, multiétnico e multilíngue.Os desafios nesta matéria vão desde o melhoramento da formação docente para contextos de diversidade cultural, o redesign curricular que inclua os conhecimentos, saberes e tecnologias ancestrais, a aprofundação da cosmovisão dos povos indígenas, a prática de uma verdadeira interculturalidade desde a educação superior, o fortalecimento da língua materna, entre outros, para prover aos futuros profissionais uma formação sólida, includente e contextualizada.

Palavras chave: educação bilíngue intercultural; formação docente; educação intercultural; História da educação latinoamericana; educação superior.

\section{PIKÜNOGETUN}

Tüfachi küzaw mew malügey ka günezuamgey chum amulen ta kimeltuchen ta $\mathrm{pu}$ kimeltuchefegealu universidad mew koneltulelu ta Educación Bilingüe Intercultural (EIB), tüfachi zugu yeniegey Universidad de San Carlos Guatemala mapu mew fey tüfey Escuela de Formación de Profesores de Enseñanza Media (EFPEM), fey chijkatuwe 2002 xipantu zew yeniey tüfey chi zugu nentual ta pu che kimeltuchefegeal fey chi zugu mew sistema educativo guatemalteco $\mathrm{ka} p \mathrm{pu}$ chegealu mülelu fey mew, koneltulelu ta kizu ñi kimeltuwün egün, kizu ñi xokiñchegen egün ka kizu ñi zugun mew egün; wenuntugey ta tüfachi zugu pepikawün mew ta kiñeke instituciones nacionales ka internacionales, fey küme amulniegey ta azkünun zugu ka küme nentugey ta carrera pregrado mew ka posgrado mew. Zewmayael tüfachi küzaw nentugey zugu ta weke küzaw mew, gümitugey zugu kiñe cuestionario mew ka ramtukagey güxam mew ta pu chijkatufe konkülelu carrera de profesorado mew, licenciatura ka maestría en EBI mew, fey tüfey pu zew xipalu, kimeltuchefe ka logkolelu EFPEM mew fey tüfey egün am ta nielu kimün ka kim küzawigün füxa chijkatuwe ruka mew ka kimnieygün ta chumlen xokiñche zugu Guatemala mapu mew.

Tüfachi küzaw tuwülgey ta chew tuwmun ta kimeltuchen kimeltuchefegeal EBI mew, fey tüfey xipay 2002 xipantu mew fey petu müley fantepu mew; tunte amulen ta antü kimfali ñi amulniegen ta carrera wenuntulu kiñe zoy küme kimeltuwün yenielu fey chi mapu ñi zugu, fey chi zugu zuamniegey ta nacional mapu mew, fey chi zugu am ta zuamniegelu Guatemala mapu mew, fey mew ta kiñe mufü azxokiñche mülejelu, mufü xokiñche ka fij kake zugun niejelu ta pu che Guatemala mew.

Zoy küme amuleal tüfachi zugu müley ñi zoy newenkonal ta chumgechi kimeltugeken ta pu kimeltuchefegealu ñi küzawal fijke mapu mew nielu fijke azxokiñche, wüñoelgetual ta chem zugu kimeltugeay, müley ta ñi niafel kuyfike kimün ka kuyfike pepikawün ta che, zoy küme güneltugeal ta chem rakizuam niey a pu kuyfike che pu indígenas, küzawgeal ta kiñe rüf interculturalidad zugu educación superior mew zoy newenkonal ta ñuke kewüh, kake zugu kafey, femgechi 
ta küme kimeltugeafuy pu kimeltuchefegealu, koneltugele ka niele fey chi mapu ñi zugu.
Kimfal hemül: kimeltuwün ери rume kewüh mew intercultural; kimeltuchen; epu rume kimeltuwün; Historia de la educación latinoamericana; educación superior.

\section{INTRODUCCIÓN}

La formación de docentes en educación bilingüe intercultural es un proceso mediante el cual la Escuela de Formación de Profesores de Enseñanza Media (EFPEM), unidad académica de la Universidad de San Carlos de Guatemala (USAC) viene desarrollando en atención a las necesidades y expectativas educativas de la población indígena proveniente de las culturas Maya, Xinca y Garífuna, dentro del marco de una formación con pertinencia cultural, étnica y lingüística.

Si bien la EFPEM viene formando docentes y profesionales para esta especialidad desde 2002, es necesario reflexionar sobre el avance y los desafíos que se tienen para mejorar dicha formación; análisis y discusión que se hace desde los propios protagonistas para la obtención de puntos de vista que evidencien el sentir de quienes son los beneficiarios directos de este proceso, como lo son los estudiantes de las diferentes carreras, egresados, profesores y autoridades educativas.

Como punto de partida se revisa el desarrollo de la formación docente en Guatemala, desde sus inicios en las Escuelas Normales, en 1835, pasando por el fomento del normalismo hasta llegar a lo que hoy conocemos como profesorado, licenciatura y maestría en educación bilingüe intercultural a nivel superior.

Visualizar una formación docente con pertinencia cultural, étnica y lingüística representa uno de los desafíos que se debe afrontar en la educación superior tomando en cuenta elementos como la reformulación del diseño curricular, el desarrollo de competencias docentes para estos contextos, la ampliación de oportunidades a estudiantes de poblaciones indígenas o bien mejorar la formación de formadores y la ejecución de investigaciones educativas que provean información para el análisis, discusión e incorporación a la práctica educativa.

El fomento de la educación bilingüe intercultural se basa en el aseguramiento de la calidad de los docentes como factor que incide en el aprendizaje de los estudiantes, lo cual conlleva no solo la implementación de modelos pedagógicos para contextos de diversidad cultural, sino el asegurar la atención de la población indígena desde los saberes ancestrales, su cultura, su idioma materno, sus costumbres y las relaciones interculturales como fuente de enriquecimiento y aprendizaje desde los grupos culturalmente identificados.

Esta investigación surge desde la propia importancia de mejorar la formación de los profesionales en educación bilingüe intercultural, partiendo de las experiencias desarrolladas en la Escuela de Formación de Profesores de Enseñanza Media (EFPEM, USAC). 


\section{Antecedentes de la formación docente en Guatemala}

\section{Las Escuelas Normales a partir de 1835}

Desde la creación, en 1835, del programa de Escuelas Normales decretado durante el gobierno del Dr. Mariano Gálvez (1831-1838), la conocida como Escuela Normal Lancasteriana ${ }^{2}$ o Escuela Normal de Primeras Letras inicia de manera sistemática la formación docente en Guatemala con la intencionalidad de dar respuesta a la falta del recurso humano preparado para la atención de los niños y jóvenes en edad escolar ${ }^{3}$.

Posteriormente, en 1879, se funda la escuela que promovería la formación de maestros especiales para la atención de personas indígenas, establecimiento educativo conocido en su época como Instituto Agrícola para Indígenas, creado por medio del decreto 474 de fecha 30 de octubre de $1893^{4}$; más tarde se cambia su nombre por el de Escuela Normal de Indígenas y finalmente por el de Escuela Normal de Preceptores Uruguay, a principios de $1924^{5}$.

Como se puede observar, la historia de estos procesos de creación de las Escuelas Normales tiene más de ciento ochenta años y particularmente la creación de una escuela normal para formar maestros para la población indígena casi cien años, y tal como lo establece González Orellana:

La precaria existencia de este centro se explica por la inexperiencia pedagógica de los receptores de la educación, pues incurrían en el error de querer discriminar la educación de los aborígenes guatemaltecos, sin tomar en consideración que se trataba de resolver un problema cuya única característica consistía en ser de naturaleza rural. ${ }^{6}$

Dentro de este contexto, no se cuenta con información del idioma utilizado en la formación de los docentes, si se toma en cuenta que este proceso estaba dirigido hacia población estudiantil indígena o aborigen, que en su mayoría pertenecía al pueblo Maya7.

De acuerdo con las políticas de cada gobierno de turno se fueron creando Escuelas Normales que se identificaban como urbanas, rurales, de educación para el hogar, de párvulos, regionales, de educación física, música; y posteriormente se establecieron las Escuelas Normales interculturales, Escuelas Norma-

2 Carlos González Orellana, Historia de la Educación en Guatemala (Guatemala: Editorial Universitaria, Universidad de San Carlos de Guatemala, 2011), 197.

3 Oscar Hugo López Rivas y José Enrique Cortez Sic, Las Escuelas Normales en Guatemala. Origen y desarrollo, crisis y situación actual (Guatemala: UPTC, 2016), 75.

4 González Orellana, Historia de la Educación, 250.

5 Ibíd.

6 Ibíd.

7 Son cuatro "los pueblos que cohabitan en el territorio guatemalteco: Maya, Garífuna, Xinca y Ladino. [...] Los idiomas mayas conforman una familia de alrededor de 22 idiomas con estructura propia”. Dirección General de Educación Bilingüe Intercultural (DIGEBI) y Ministerio de Educación (MINEDUC), http://www.mineduc.gob.gt/DIGEBI/. 
les bilingües interculturales, según el interés gubernamental y las necesidades de formación en función del desarrollo educativo del país.

La creación de las Escuelas Normales, presentada dentro de una línea de tiempo, permite entenderlas como de primera, segunda y tercera generación por la importancia e incidencia que tuvieron en la formación de maestros y maestras para el Sistema Educativo de Guatemala. Para comprender los procesos de la creación de las Escuelas Normales la historia se puede rastrear desde 1872, tal como se describe en la tabla n. ${ }^{\circ} 1$.

Tabla 1: Institutos y Escuelas Normales en Guatemala a partir de 1872

\begin{tabular}{|c|c|c|}
\hline Año & Escuelas o institutos normales & Ciudad \\
\hline 1872 & Instituto Normal de Quetzaltenango & Quetzaltenango \\
\hline 1874 & Instituto Normal de Antigua Guatemala & Antigua Guatemala \\
\hline 1875 & Escuela Normal Central para varones & Guatemala \\
\hline 1876 & Instituto Normal de Chiquimula & Chiquimula \\
\hline 1879 & Escuela Normal de Señoritas & Guatemala \\
\hline 1893 & Escuela Normal de San Marcos & San Marcos \\
\hline 1895 & Instituto Normal de Jalapa & Jalapa \\
\hline 1928 & Escuela Normal de Maestras de Párvulos & Guatemala \\
\hline 1929-1932 & Funcionó la Escuela Normal Superior & Guatemala \\
\hline 1944 & Instituto Normal Centro América (INCA) & Guatemala \\
\hline 1944 & Instituto Normal Mixto Rafael Aqueche & Guatemala \\
\hline 1944 & Instituto Normal Mixto Nocturno & Guatemala \\
\hline 1944 & Escuela de Maestras para Párvulos a nivel Superior & Guatemala \\
\hline 1944 & Escuela de Profesores de Educación Física & Guatemala \\
\hline 1944 & Escuela Normal Rural “La Alameda” & Chimaltenango \\
\hline 1944 & Escuela Normal Rural de Totonicapán & Totonicapán \\
\hline 1944 & Escuela Normal Rural n. ${ }^{\circ} 4$, Salamá & Salamá, B. V. \\
\hline 1945 & Instituto Normal Mixto del Norte & Cobán, A. V. \\
\hline 1956 & Escuela de Educación para el Hogar "Marion G. Bock" & Guatemala \\
\hline 1959 & Escuela Normal Educación Física & Guatemala \\
\hline 1959 & $\begin{array}{l}\text { Escuela Normal de Maestros de Educación Musical } \\
\text { "Jesús María Alvarado" }\end{array}$ & Guatemala \\
\hline
\end{tabular}

Fuente: Textos para el debate educativo, n. ${ }^{\circ}$ (Guatemala: PREAL, FLACSO, 2010).

Entre 1872 y 1959 fueron creadas 21 Escuelas Normales para los niveles de primaria urbana o rural, de párvulos, para la formación de educadoras para el hogar, de música y de educación física.

Quince años después de haber fundado la escuela de música se crearon dos escuelas regionales, con diseños experimentales y con modelo de coeducación, con internado; y el ingreso de estudiantes se realizó por un proceso de selección a partir de $6 . .^{\circ}$ de primaria, con una duración de cinco años de formación, organizado por semestres, cuatro años de estudios y un año de práctica docente, en el lugar de origen del estudiante. 
Tabla 2: Escuelas Normales Regionales

\begin{tabular}{|c|c|c|}
\hline Año & Escuelas regionales & Ubicación \\
\hline 1974 & $\begin{array}{c}\text { Escuela Normal Regional de Occidente } \\
\text { (ENRO) Santa Lucía Utatlán, Sololá }\end{array}$ & Santa Lucía Utatlán, Sololá \\
\hline 1978 & $\begin{array}{c}\text { Escuela Normal Regional de Occidente - } \\
\text { ENRO- Monjas, Jalapa }\end{array}$ & Monjas, Jalapa \\
\hline
\end{tabular}

Fuente: elaboración propia a partir del documento Las Escuelas Normales en Guatemala. Origen y desarrollo, crisis y situación actual (2016).

La ENRO de Santa Lucía Utatlán, Sololá, fue creada exclusivamente para estudiantes indígenas de las diferentes regiones del país con población indígena; sin embargo, para el desarrollo de las clases, se utilizaba como lengua franca el español, teniendo únicamente un curso titulado "Lenguas indígenas de Guatemala" ${ }^{\prime}$, desarrollado en español.

Finalmente, a partir del año 2000, fueron creadas otras Escuelas Normales para dar respuesta a la demanda educativa, según el contexto cultural y lingüístico del país, así como a las necesidades de formación de docentes para el desarrollo de la educación física.

Tabla 3: Escuelas Normales creadas a partir del año 2000

\begin{tabular}{|c|c|}
\hline Nombre & Cantidad \\
\hline Escuelas Normales Bilingües Interculturales & 9 \\
\hline Escuelas Normales Interculturales & 4 \\
\hline Escuelas Normales de Educación Física & 22 \\
\hline Total & 35 \\
\hline
\end{tabular}

Fuente: elaboración propia a partir de documento Las Escuelas Normales en Guatemala.

Origen y desarrollo, crisis y situación actual (2016).

Cabe resaltar que de las 35 Escuelas Normales creadas, 9 se ubicaron para atender población estudiantil indígena en áreas de diversidad cultural, étnica y lingüística, formando docentes para los niveles de educación preprimaria y primaria bilingüe intercultural ${ }^{9}$.

Dentro de este grupo de establecimientos educativos, la ENRO de Sololá y las nueve Escuelas Normales Bilingües Interculturales estaban vinculadas a la formación de docentes para la atención de niños y niñas de escuelas del nivel preprimario y primario con población indígena ${ }^{10}$.

8 Biblioteca Escuela Normal Regional de Occidente, "Historia de la ENRO, Sololá". Documento inédito de la dirección del establecimiento educativo (2018).

9 López Rivas y Cortez Sic, Las Escuelas Normales, 75.

10 La cultura Maya está compuesta por 22 grupos étnicos, situados principalmente en la zona noroccidental del país (DIGEBIMINEDUC). 


\section{Estrategia para la nueva Formación Inicial Docente (FID)}

Luego de una serie de análisis, discusión y confrontación con los directores, docentes y estudiantes de las Escuelas Normales que formaban, a nivel medio, a maestros de educación primaria, el Gobierno de la República de Guatemala, a través del Ministerio de Educación, creó la "Estrategia para una educación de calidad para la niñez y juventud guatemalteca"11, que impulsó a partir del año 2013, en convenio con la Universidad de San Carlos de Guatemala (USAC), firmando un Acuerdo Específico para la Formación Inicial Docente (FID) ${ }^{12}$, en donde se establece la organización de la nueva forma de preparación de los maestros a nivel universitario.

El nuevo modelo de formación docente estableció dos etapas de preparación académica, la primera de las cuales estaba constituida en el nivel medio, con dos años de duración, para obtener el título de bachillerato en educación y sus respectivas especialidades; proceso que, con fecha 8 de octubre del 2013, los acreditaba para continuar sus estudios para la docencia en la USAC a partir del 2015, con una duración de tres años, becados por parte del Ministerio de Educación, para obtener el título de Profesor de Educación Primaria Intercultural, Profesor de Educación Primaria Bilingüe Intercultural, Profesor de Educación Física, Profesor de Educación Artística y Profesor de Educación en Productividad y Desarrollo ${ }^{13}$.

Las unidades académicas de la USAC encargadas de estos procesos son: La Facultad de Humanidades, los Centros Regionales, la Escuela de Formación de Profesores de Enseñanza Media (EFPEM) y la Escuela de Ciencia y Tecnología de la Actividad Física y el Deporte (ECTAFIDE).

Dentro de este marco regulativo, luego de cumplir con el período de formación establecida, ha egresado la primera promoción de la nueva formación inicial docente de la Universidad de San Carlos de Guatemala.

Tabla 4: Profesores graduados en la nueva Formación Inicial Docente

\begin{tabular}{|c|c|}
\hline Especialidad & Cantidades \\
\hline Educación Primaria Intercultural & 366 \\
\hline Educación Primaria Bilingüe Intercultural & 320 \\
\hline Expresión artística con especialidad en Educación Musical & 7 \\
\hline Productividad y desarrollo & 37 \\
\hline Educación física & 212 \\
\hline Total graduados & 942 \\
\hline
\end{tabular}

Fuente: Ministerio de Educación, 2019.

Los 942 profesores graduados en Educación Primaria con sus diferentes especialidades a nivel superior es un logro importante y por lo tanto un avance

11 Ministerio de Educación, "Estrategia para una educación de calidad para la niñez y juventud guatemalteca" (Guatemala: 2013).

12 "Acuerdo marco entre el Ministerio de Educación y la Universidad de San Carlos de Guatemala" (Guatemala, 2013).

13 Ibíd. 
en materia de formación docente, siendo la primera cohorte en obtener el título universitario en función del convenio marco establecido entre el Ministerio de Educación y la USAC a través de sus diferentes unidades responsables de la implementación de la Formación Inicial Docente (FID) en el ámbito nacional ${ }^{14}$.

\section{Experiencia universitaria en la formación de docentes en Educación Bilin- güe Intercultural}

Inicio y desarrollo de la formación docente en Educación Bilingüe Intercultural en la USAC

Desde su fundación, el 31 de enero de 1676, y con más de trescientos años de trascendencia académica y de incidencia nacional en los ámbitos educativo, social, cultural, político, económico, entre otros, la Universidad de San Carlos de Guatemala ha venido formando profesionales para la educación en diferentes unidades académicas, según las demandas de formación docente para la inserción en el Sistema Educativo Nacional (SEN).

La Escuela de Formación de Profesores de Enseñanza Media (EFPEM), unidad académica fundada en $1968^{15}$ como escuela de la Facultad de Humanidades a través de un convenio interinstitucional entre el Ministerio de Educación, la Universidad de San Carlos de Guatemala y la Organización de las Naciones Unidas para la Educación, la Ciencia y la Cultura (UNESCO), fue creada por la misma necesidad de formar profesores para laborar en el nivel medio del Sistema Educativo Nacional, en las especialidades de las ciencias, Matemática y Física, Química y Biología.

En 1998 la EFPEM se independizó de la Facultad de Humanidades para transformarse en una Escuela no Facultativa y tener su propio desarrollo académico en la formación de docentes para el SEN; es así como, además de las carreras científicas, económico contables, lengua y literatura e informática y computación del profesorado para el nivel medio, amplía su oferta de estudios e implementa carreras en los ámbitos de licenciatura y maestrías con el objetivo de profundizar la formación del recurso humano con las calidades correspondientes.

La EFPEM ha sido la unidad académica de la USAC que ha avanzado en la formulación de diseños curriculares tomando en cuenta las necesidades de formación docente para contextos multiculturales, multilingües y multiétnicos y ha dado pasos trascendentales en la formación de profesionales en la Educación Bilingüe Intercultural (EBI), teniendo como punto de partida el año $2002^{16}$ a través de convenios y subvenciones con instituciones nacionales e internacionales,

14 Informe de implementación de la FID por la Dirección General de Gestión de la Calidad Educativa (DIGECADE) y de la Dirección General de Educación Bilingüe Intercultural (DIGEBI) Ministerio de Educación de Guatemala, 2019.

15 Óscar Peláez Almengor, La Escuela de Formación de Profesores de Enseñanza Media EFPEM. ¿Un poema pedagógico? (Guatemala: CEUR, 2014), 89.

16 "Informe de labores. Dirección de Escuela de Formación de Profesores de Enseñanza Media -EFPEM-" (Guatemala, 2018). 
implementándose carreras para este ámbito académico y dando oportunidades a estudiantes provenientes de los diferentes grupos indígenas del país.

Los procesos de formación docente en la EFPEM en la Educación Bilingüe Intercultural parten de las transformaciones académicas respaldadas por las políticas académicas de la USAC como un compromiso de asegurar la sostenibilidad y desarrollo de la formación de profesionales que contribuyan al desarrollo de la sociedad con pertinencia cultural, étnica y lingüística.

Dentro de este marco y tomando en cuenta el tiempo transcurrido desde el inicio de la formación docente en la Educación Bilingüe Intercultural y después de doce años de la implementación, es necesario enfrentarse a nuevos desafíos que mejoren las condiciones en la formación del recurso humano, tomando en cuenta la trascendencia nacional y de cara a las necesidades existentes en este ámbito de acción ${ }^{17}$.

\section{La Educación Bilingüe Intercultural y sus principios pedagógicos}

Es importante reconocer que formar docentes para el ámbito universitario en Educación Bilingüe Intercultural en el contexto guatemalteco requiere de conocimiento pleno de las particularidades que tienen los aprendizajes de los niños, niñas y jóvenes según el nivel académico donde se encuentran. La preparación de docentes altamente efectivos debe tener estándares de calidad que impliquen un desempeño exitoso en las áreas de trabajo donde prestarán sus servicios como mediadores del aprendizaje en población escolar indígena.

Sobre el particular es necesario, en primer lugar, que tanto el formador de formadores como de estudiantes de las carreras en Educación Bilingüe Intercultural tengan pleno conocimiento en esta área de conocimiento para establecer las mejores formas de generar los procesos de formación. Dentro de este caso, la formación docente debe considerar de manera oportuna los principios siguientes:

i. Los estudiantes desarrollan capacidades de expresión oral y escrita en dos lenguas cuando aprenden las disciplinas escolares presentadas en materiales escritos en las dos lenguas.

ii. Aprender la segunda lengua es más fácil cuando el enfoque metodológico enfatiza tanto en la necesidad de comunicación (producir y comprender textos) como en la reflexión sobre el lenguaje.

iii. Aprender a hablar, leer, escribir y razonar en nuevo idioma requiere de un ambiente escolar en el que los estudiantes tengan múltiples oportunidades de escribir y hablar, en contextos didácticos específicos que tengan sentido para ellos ${ }^{18}$.

Estos principios deben ser comprendidos en su amplia dimensión para que a partir de todo el proceso formativo se analicen y apliquen en los diferentes cur-

17 "Carreras regulares en la EFPEM" (documento inédito), Secretaría Académica de EFPEM-USAC (Guatemala, 2017).

18 Edivanda Mugrabi, Teoría y práctica de la pedagogía del texto (Guatemala: USAC-Enfants du Monde, 2019), 59-60. 
sos de las carreras de profesorado, licenciatura y maestría, dentro de las lógicas de profundización y discusión permanentes.

Por otra parte, la formación docente universitaria debe considerar los contextos de diversidad cultural para preparar al futuro profesional de modo tal que pueda dar respuesta a las necesidades de la población indígena, enfatizando en la Educación Bilingüe Intercultural y en los conocimientos de los pueblos indígenas como un mecanismo de reconocimiento y práctica de los saberes ancestrales desde una educación propia para comprender la vida y desarrollo de las comunidades educativas para avanzar en otras experiencias de otras culturas, como es el caso del Estado guatemalteco ${ }^{19}$. Es el enfoque educativo orientado a la satisfacción de necesidades educativas de una sociedad multiétnica ${ }^{20}$ y multilingüe y al desarrollo de una imagen, autoimagen positiva en todos los educandos, y particularmente entre los estudiantes que pertenecen a los pueblos indígenas que componen el país ${ }^{21}$.

La formación del profesorado en contextos de diversidad cultural debe propiciar la pluralidad cultural y el conocimiento y práctica de una educación intercultural que permita desde la academia el diálogo crítico y la sociedad de la cooperación ${ }^{22}$.

Estas experiencias de fortalecimiento de la Educación Bilingüe Intercultural tienen mucha relación con otras en el ámbito latinoamericano, tal el caso del grupo de maestras que trabajan en la institución etnoeducativa Sierra Nevada, Colombia, que busca una supremacía en el diseño curricular flexible, democrático y participativo ${ }^{23}$ con diferentes grupos étnicos como elementos básicos para una educación desde el contexto.

Dentro del marco de estudio para el presente caso de investigación se considerará el desarrollo de la formación docente en Educación Bilingüe Intercultural en la Escuela de Formación de Profesores de Enseñanza Media, unidad académica de la USAC, que ha ido en la vanguardia en este tipo de experiencias a partir del 2002.

\section{Oferta académica en la EFPEM-USAC}

Aun cuando la USAC tiene bajo su responsabilidad la formación de profesores por medio de diferentes unidades académicas, es necesario analizar la formación académica de los docentes en las carreras de educación preprimaria, primaria, media, licenciatura y maestría para valorar el avance y las mejoras

19 Demetrio Cojtí Cuxil, Glosario sobre la diversidad étnica y cultural de Guatemala (Guatemala: Editorial Cholsamaj, 2010 ), 32.

20 Mario Roberto Morales, Estética y política de la interculturalidad (Guatemala: Ediciones Superiores, 2017), 14.

21 Jorge Raymundo Velásquez, Educación bilingüe intercultural o educación intercultural bilingüe (Guatemala: Universidad Rafael Landívar-Cara Parens, 2015), 27.

22 María Lafuente Guantes, "Educación intercultural y formación del profesorado", Revista historia de la educación latinoamericana 19, n. 29 (2017): 108. https://doi.org/10.19053/01227238.7554 (18/8/2019).

23 María Domínguez Garrido, Adiela Ruiz Cabezas y Antonio Medina Rivilla, Experiencias docentes y su proyección en la identidad profesional: El caso de las maestras de Santa Marta y su entorno (Tunja: UPTC-Búhos Editores, 2017), 121. 
que se deben integrar como fuente de enriquecimiento, particularmente en la formación bilingüe intercultural.

El desarrollo de las carreras referidas en el párrafo anterior se analiza desde la perspectiva de la implementación y la población objetivo, el estado de arte para este caso se visualiza a continuación:

Tabla 5: Formación docente en Educación Bilingüe Intercultural en EFPEM

\begin{tabular}{|c|c|c|c|c|}
\hline $\begin{array}{c}\text { n. } \\
\text { orden }\end{array}$ & Oferta académica & Plan & $\begin{array}{c}\text { Tipo de } \\
\text { presupuesto }\end{array}$ & Población objetivo \\
\hline 1 & $\begin{array}{c}\text { Profesorado en } \\
\text { Educación Preprimaria } \\
\text { Bilingüe Intercultural }\end{array}$ & Sabatino & Autofinanciable & $\begin{array}{c}\text { Docentes en servicio en } \\
\text { el nivel preprimario del } \\
\text { sector público }\end{array}$ \\
\hline 2 & $\begin{array}{c}\text { Profesorado en } \\
\text { Educación Primaria } \\
\text { Bilingüe Intercultural }\end{array}$ & Sabatino & Autofinanciable & $\begin{array}{c}\text { Docentes en servicio en el } \\
\text { nivel primario del sector } \\
\text { público }\end{array}$ \\
\hline 3 & $\begin{array}{c}\text { Profesorado en } \\
\text { Enseñanza Media en } \\
\text { Educación Bilingüe } \\
\text { Intercultural }\end{array}$ & Sabatino & $\begin{array}{c}\text { Inició como proceso } \\
\text { autofinanciable; se } \\
\text { convirtió en carrera } \\
\text { regular }\end{array}$ & $\begin{array}{c}\text { Estudiantes indígenas con } \\
\text { interés en formarse en esta } \\
\text { área (en su mayoría) }\end{array}$ \\
\hline 5 & $\begin{array}{c}\text { Licenciatura en } \\
\text { Educación Bilingüe } \\
\text { Intercultural }\end{array}$ & Sabatino & $\begin{array}{c}\text { Inició como proceso } \\
\text { autofinanciable; se } \\
\text { convirtió en carrera } \\
\text { regular }\end{array}$ & $\begin{array}{c}\text { Estudiantes indígenas con } \\
\text { interés en formarse en esta } \\
\text { área (en su mayoría) }\end{array}$ \\
\hline Maestría en Educación & Sabatino & Autofinanciable & $\begin{array}{c}\text { Selección de estudiantes } \\
\text { indígenas por parte de los } \\
\text { vinculados al convenio de } \\
\text { cooperación. }\end{array}$ \\
\hline
\end{tabular}

Fuente: Elaboración propia con base en datos de EFPEM (2018).

Se evidencia que en la formación docente en Educación Bilingüe Intercultural aún persiste el carácter autofinanciable en la mayoría de las carreras que ofrece la EFPEM-USAC: tres de cuatro carreras tienen esta característica, lo que constituye un reto para la institución regularizar esta formación para que sea sostenible técnica, administrativa y financieramente y así aumentar la oferta educativa para estudiantes que están interesados en continuar estudios a nivel universitario.

\section{Descripción de las carreras en Educación Bilingüe Intercultural en la EFPEM}

A partir de 2002 se inició la formación docente en Educación Bilingüe Intercultural, con ocasión de un convenio de cooperación con la fundación Rigoberta Menchú Tum ${ }^{24}$, referido a dar oportunidad de formación universitaria a jóvenes indígenas que deseaban estudiar el profesorado en Educación Media en Educación Bilingüe Intercultural con énfasis en la cultura Maya, plan sabatino.

24 "Informe anual de acciones académicas de EFPEM", Secretaria académica EFPEM-USAC (Guatemala, 2017). 
Profesorado en Educación Media en Educación Bilingüe Intercultural con énfasis en la cultura Maya, plan sabatino

Tabla 6: Pénsum de estudios de PEM en EBI

\begin{tabular}{|c|c|}
\hline PRIMER SEMESTRE & SEGUNDO SEMESTRE \\
\hline Lenguaje I: Estudios gramaticales & Lenguaje II: Comunicación \\
\hline Técnicas de investigación y estudio & Educación y Educación Popular \\
\hline Pedagogía I & Pedagogía II \\
\hline Cultura Maya e interculturalidad & Fundamentos de Educación Maya \\
\hline Lingüística Maya & Idioma Maya I \\
\hline III SEMESTRE & IV SEMESTRE \\
\hline Investigación Social & Desarrollo del pensamiento crítico y creativo \\
\hline Psicología del aprendizaje & Evaluación Escolar I \\
\hline Educación bilingüe intercultural & Metodología de la Educación Bilingüe Intercultural \\
\hline Idioma Maya II & Matemática Maya II \\
\hline Matemática Maya I & Cultura y género \\
\hline V SEMESTRE & VI SEMESTRE \\
\hline Historia de Guatemala I & Naturaleza y Salud \\
\hline Didáctica del idioma Maya & Diseño curricular \\
\hline Evaluación Escolar II & Ciencia y tecnología Maya \\
\hline Cultura y Género & Didáctica especial del idioma español y la literatura \\
\hline Introducción a la docencia I & Práctica docente \\
\hline
\end{tabular}

Fuente: EFPEM-USAC (2018).

Los profesores egresados de este profesorado se acreditan para laborar como docentes en el ciclo básico o diversificado del Sistema Educativo Nacional; actualmente se han graduado mil quinientos profesores ${ }^{25}$ de diferentes grupos étnicos.

Se resalta la importancia de la transición de un proceso autofinanciable con el apoyo financiero de instituciones que se han interesado en el fortalecimiento de la Educación Bilingüe Intercultural, generando convenios con la EFPEM-USAC, unidad académica que siempre se ha caracterizado por el fomento y respaldo a la educación de los pueblos indígenas de Guatemala y, por lo consiguiente, en la actualidad esta carrera de profesorado se ha convertido en una carrera regular que se imparte en el plan sabatino como el resto de carreras que tiene la EFPEM.

Transcurridos siete años desde la creación del profesorado en Enseñanza Media en Educación Bilingüe Intercultural, llegó una etapa de suma importancia para la Universidad de San Carlos de Guatemala, y por ende para la Escuela de Formación de Profesores de Enseñanza Media, debido a que el Ministerio de Educación comenzó a requerir servicios técnicos para mejorar las habilidades de docentes en servicio en el Sistema Educativo Nacional y con base en un acuerdo marco firmado entre las partes, a partir de julio del 2009 se dio inicio al Programa Académico de Desarrollo Profesional Docente, con los siguientes profesorados:

25 Víctor Coyote Guitzol, "Educación Bilingüe Intercultural”, Revista Del blog a la Revista, año 2, Edición 6, (2018): 15. 
Profesorado en Educación Preprimaria y profesorado en Educación Primaria, ambos en Educación Bilingüe Intercultural. Este proceso tiene su fundamentación en el documento "Bases para el Diseño del Sistema Nacional de Formación Docente en Guatemala", en consenso y con participación de la Asamblea Nacional del Magisterio, publicado por la Universidad de San Carlos de Guatemala en el mes de junio $2008^{26}$. En las tablas 7 y 8 se puede revisar la conformación del pénsum de estudios que era parte del rediseño curricular de la formación docente en Educación Bilingüe Intercultural para docentes en servicio del sector público.

Tabla 7: Pénsum de estudios para profesorado en Educación Preprimaria Bilingüe Intercultural

\begin{tabular}{|c|c|}
\hline PRIMER SEMESTRE & SEGUNDO SEMESTRE \\
\hline Realidad sociocultural de Guatemala & Desarrollo evolutivo del niño \\
\hline Educación multicultural e intercultural & Psicopedagogía \\
\hline Investigación y desarrollo profesional & Administración y legislación educativa \\
\hline Matemática y pensamiento lógico & Planificación y evaluación de los aprendizajes \\
\hline Comunicación y lenguaje & Ética profesional y desempaño docente \\
\hline III SEMESTRE & IV SEMESTRE \\
\hline Tics aplicada a la educación & $\begin{array}{c}\text { Destrezas de aprendizaje desde la cosmovisión } \\
\text { de los pueblos y su aprendizaje }\end{array}$ \\
\hline $\begin{array}{c}\text { Introducción al diseño y desarrollo } \\
\text { curricular bilingüe intercultural }\end{array}$ & $\begin{array}{c}\text { Comunicación y Lenguaje desde la cosmovisión } \\
\text { de los pueblos y su aprendizaje }\end{array}$ \\
\hline $\begin{array}{c}\text { Atención a las necesidades educativas } \\
\text { especiales }\end{array}$ & $\begin{array}{c}\text { Medio social y natural desde la cosmovisión de } \\
\text { los pueblos y su aprendizaje }\end{array}$ \\
\hline $\begin{array}{c}\text { Aprendizaje de la Lengua Materna (L1: } \\
\text { idioma Garífuna, Maya y/o Xinca) }\end{array}$ & $\begin{array}{c}\text { Expresión artística desde la cosmovisión de los } \\
\text { pueblos y su aprendizaje }\end{array}$ \\
\hline $\begin{array}{c}\text { Atención a la niñez de } 0 \text { a } 6 \text { años a través de } \\
\text { las modalidades formales y no formales }\end{array}$ & $\begin{array}{c}\text { Educación física desde la cosmovisión de los } \\
\text { pueblos y su aprendizaje }\end{array}$ \\
\hline
\end{tabular}

Fuente: EFPEM-USAC. PADEP, 2009.

Tabla 8: Pénsum de estudios para profesorado en Educación Primaria Bilingüe Intercultural

\begin{tabular}{|c|c|}
\hline PRIMER SEMESTRE & SEGUNDO SEMESTRE \\
\hline Realidad sociocultural de Guatemala & Desarrollo evolutivo del niño \\
\hline Educación multicultural e intercultural & Psicopedagogía \\
\hline Investigación y desarrollo profesional & Administración y legislación educativa \\
\hline Matemática y pensamiento lógico & Planificación y evaluación de los aprendizajes \\
\hline Comunicación y lenguaje & Ética profesional y desempeño docente \\
\hline
\end{tabular}

26 Oscar Hugo López Rivas, Bases para el Diseño del Sistema Nacional de Formación Docente en Guatemala (Guatemala: Ediciones USAC, 2013). 


\begin{tabular}{|c|c|}
\hline III SEMESTRE & IV SEMESTRE \\
\hline Tics aplicada a la educación & $\begin{array}{c}\text { Ciencias sociales, formación ciudadana, } \\
\text { productividad y desarrollo desde la cosmovisión } \\
\text { de los pueblos y su aprendizaje }\end{array}$ \\
\hline $\begin{array}{c}\text { Introducción al diseño y desarrollo } \\
\text { curricular bilingüe intercultural }\end{array}$ & $\begin{array}{c}\text { Expresión artística desde la cosmovisión de los } \\
\text { pueblos y su aprendizaje }\end{array}$ \\
\hline $\begin{array}{c}\text { Atención a las necesidades educativas } \\
\text { especiales }\end{array}$ & $\begin{array}{c}\text { Educación física desde la cosmovisión de los } \\
\text { pueblos y su aprendizaje }\end{array}$ \\
\hline $\begin{array}{c}\text { Aprendizaje de la Lengua Materna (L1: } \\
\text { idioma Garífuna, Maya y/o Xinca) }\end{array}$ & $\begin{array}{c}\text { Ciencias Naturales y tecnología desde la } \\
\text { cosmovisión de los pueblos y su aprendizaje }\end{array}$ \\
\hline $\begin{array}{c}\text { Matemática desde la cosmovisión de los } \\
\text { pueblos y su aprendizaje }\end{array}$ & $\begin{array}{c}\text { Área de Comunicación y Lenguaje desde la } \\
\text { cosmovisión de los pueblos y su aprendizaje }\end{array}$ \\
\hline
\end{tabular}

Fuente: EFPEM-USAC, Programa Académico de Desarrollo Profesional Docente, 2009.

El primero y segundo semestres de ambos profesorados tienen un área común con los profesorados de educación intercultural, mientras que los semestres tercero y cuarto establecen el área de la especialidad para el profesorado bilingüe intercultural, tanto para preprimaria como para primaria.

Para estos profesorados se requiere que todo docente que ingresa a esta carrera debe estar laborando en el Sistema Educativo Nacional, sector público en los niveles preprimario y primario, cuyos establecimientos educativos estén vinculados a la caracterización sociolingüística ${ }^{27}$ que identifica la Dirección General de Educación Bilingüe Intercultural, dependencia del Ministerio de Educación ${ }^{28}$.

En la tabla 9 se presentan las estadísticas del proceso de profesionalización para docentes que han participado en los profesorados de preprimaria y primaria, así como la primera cohorte de licenciatura impartida por la EFPEM, unidad académica de la USAC.

Tabla 9: Número de egresados del Programa Académico de Desarrollo Profesional Docente (PADEP/D) Educación Bilingüe Intercultural

\begin{tabular}{|c|c|c|c|c|}
\hline Años & Cohorte & $\begin{array}{c}\text { Profesorado } \\
\text { preprimaria }\end{array}$ & $\begin{array}{c}\text { Profesorado } \\
\text { primaria }\end{array}$ & Total \\
\hline $2009-2010$ & $1 .^{\text {a }}$ & 139 & 689 & 828 \\
\hline $2011-2012$ & $2 .^{\text {a }}$ & 260 & 1199 & 1459 \\
\hline $2013-2014$ & $3 .^{\text {a }}$ & 440 & 1844 & 2284 \\
\hline $2014-2015$ & $4 .^{\text {a }}$ & 12 & 89 & 101 \\
\hline $2015-2016$ & $5 .^{\text {a }}$ & 275 & 1275 & 1550 \\
\hline $2017-2018$ & $6 .^{\text {a }}$ & 237 & 801 & 1038 \\
\hline \multicolumn{2}{|c|}{ Totales } & 1363 & 5897 & 7260 \\
\hline
\end{tabular}

Fuente: Ministerio de Educación. DIGEBI, datos al 2018.

Si bien es cierto que tanto el Ministerio de Educación como la Universidad de San Carlos de Guatemala han realizado el esfuerzo técnico, administrativo y

27 Ministerio de Educación de Guatemala, Dirección General de Educación Bilingüe Intercultural, "La Educación Bilingüe Intercultural en el Sistema Educativo Nacional. Líneas generales" (Guatemala: 2013), 4.

28 Ibíd. 
académico para la formación de docentes en Educación Bilingüe Intercultural, de los $8305^{29}$ maestros que laboran en preprimaria bilingüe, sector oficial, únicamente 1363 maestros se han graduado al 2018 dentro de la profesionalización docente, lo cual resulta preocupante para la atención de los niños y niñas que requieren del fortalecimiento de esta modalidad educativa.

De igual manera, en el nivel de educación primaria bilingüe intercultural, el avance en materia de profesionalización establece que de los 29650 profesores indígenas ${ }^{30}$ que laboran con niños y niñas en contextos multiétnicos y multilingües, 5897 docentes que han participado en el Programa Académico de Desarrollo profesional Docente (PADEP/D) se han graduado, deduciéndose que aún se requiere de mayor cobertura del programa para dar oportunidad al resto de docentes que no han participado en dicho programa.

El Ministerio de Educación y la Asamblea Nacional del Magisterio Nacional acordaron la implementación de la Licenciatura en educación preprimaria y primaria con énfasis en educación bilingüe intercultural, siempre para docentes en servicio en estos niveles educativos, del sector oficial, estableciendo carta de entendimiento con la Escuela de Formación de Profesores de Enseñanza Media para el inicio y desarrollo de la licenciatura. La licenciatura actualmente se encuentra en la etapa de implementación, tal como lo demuestran los datos de la tabla n. ${ }^{\circ} 10$.

Tabla 10: Número de inscritos entre 2017 y 2019

\begin{tabular}{|c|c|c|c|}
\hline Año & Preprimaria & Primaria & Total \\
\hline $2017-2019$ & 533 & 1,961 & 2494 \\
\hline
\end{tabular}

Fuente: Ministerio de Educación - DIGEBI, 2018.

Licenciatura en Educación Bilingüe Intercultural con énfasis en cultura Maya. La EFPEM ha institucionalizado la licenciatura en Educación Bilingüe Intercultural, en plan sabatino, donde ingresan estudiantes que deseen continuar estudios, habiéndose graduado a la fecha setenta profesionales ${ }^{31}$ con el grado de licenciatura.

Los participantes en esta carrera son de procedencia indígena en su mayoría de diferentes grupos étnicos, particularmente de la cultura Maya.

La formación de los profesionales en Educación Bilingüe Intercultural se vincula al reencuentro con la historia de sus propios orígenes, las formas de vida, la naturaleza y la cosmogonía indígena ${ }^{32}$, dentro de otros elementos fundamentales para fortalecer la identidad cultural, la interculturalidad y las buenas prácticas pedagógicas.

29 Ministerio de Educación, “Anuario estadístico. Personal docente indígena que labora” (Guatemala: 2016).

30 Ibíd.

31 Escuela de Formación de Profesores de Enseñanza Media, EFPEM-USAC (Guatemala: 2017).

32 Ibíd. 
Tabla 11: Pénsum de estudios para la Licenciatura en Educación Bilingüe Intercultural con énfasis en cultura Maya

\begin{tabular}{|c|c|}
\hline PRIMER SEMESTRE & SEGUNDO SEMESTRE \\
\hline Legislación educativa & Métodos de aprendizaje del idioma Maya \\
\hline Contexto sociocultural de Guatemala & Currículo \\
\hline Pedagogía de la EBI & Laboratocación lingǘstica I \\
\hline Laboratorio del idioma Maya I & $\begin{array}{c}\text { EBaya II } \\
\text { IV SEMESTRE }\end{array}$ \\
\hline $\begin{array}{c}\text { Políticas educativas y educación para pueblos } \\
\text { indígenas }\end{array}$ & $\begin{array}{c}\text { Elaboración de materiales educativos para la } \\
\text { III SEMESTRE }\end{array}$ \\
\hline $\begin{array}{c}\text { Métodos de aprendizaje del idioma español } \\
\text { como L1 y L2 }\end{array}$ & Sociolingüística \\
\hline Planificación lingüística II & Diseño y elaboración de proyectos educativos \\
\hline Laboratorio del idioma español & Diseño y elaboración de textos educativos \\
\hline Psicolingüística & Seminario \\
\hline Sistematización de experiencias educativas & Fural \\
\hline
\end{tabular}

Fuente: EFPEM-USAC, 2017.

Maestría en Educación Bilingüe Intercultural. Este proceso de formación se llevó a cabo en las modalidades presencial, a distancia y e-learning, con la participación de estudiantes indígenas, en su mayor porcentaje. Este postgrado se llevó a cabo a partir del 2013, a través del autofinanciamiento dadas las condiciones económicas que conlleva el desarrollo de una carrera de esta naturaleza en la EFPEM - USAC.

El autofinanciamiento se ha generado con el apoyo de instituciones que velan por el fortalecimiento de la Educación Bilingüe Intercultural y de la formación de profesionales. Actualmente se han graduado diez profesionales con el título de magíster en Educación Bilingüe Intercultural.

La tabla 12 presenta el pénsum de estudios de la maestría en Educación Bilingüe Intercultural.

Tabla 12: Pénsum de estudios para la maestría en Educación Bilingüe Intercultural. EFPEM-USAC

\begin{tabular}{|c|c|}
\hline PRIMER SEMESTRE & SEGUNDO SEMESTRE \\
\hline Gnoseología & Epistemología de la educación \\
\hline Fundamentos de la EBI & Cultura e interculturalidad \\
\hline $\begin{array}{c}\text { Problemática y conceptos didácticos } \\
\text { investigativo }\end{array}$ & Contextualización del proceso didáctico \\
\hline III SEMESTRE & $\begin{array}{c}\text { Seminario de Investigación II: } \\
\text { Investigación y trabajo de campo }\end{array}$ \\
\hline Ciencias del lenguaje & Psicología del desarrollo humano \\
\hline Enseñanza aprendizaje bilingüe & Enseñanza aprendizaje bi-plurilingüe \\
\hline Didáctica y metodología & Dispositivos didácticos para EBI \\
\hline $\begin{array}{c}\text { Seminario de Investigación III: Análisis e } \\
\text { interpretación de datos }\end{array}$ & $\begin{array}{c}\text { Seminario de Investigación IV: El informe } \\
\text { de investigación como género textual }\end{array}$ \\
\hline
\end{tabular}

Fuente: EFPEM-USAC, 2018. 
Los estudiantes involucrados en esta carrera han sido mayormente profesionales que laboran o han laborado en dependencias del Ministerio de Educación para aumentar su formación en el área de la educación bilingüe intercultural, particularmente con la Dirección General de Educación Bilingüe Intercultural (DIGEBI) y sus representantes delegados en Direcciones Departamentales de Educación ${ }^{33}$.

Desde el año 2002, cuando la administración de la Escuela de Formación de Enseñanza Media tomó la decisión de apostar por el desarrollo educativo para incidir en el Sistema Educativo Nacional a través de formar profesionales en Educación Bilingüe Intercultural, el avance en esta materia ha sido extraordinario, tal como lo expresa el director de la EFPEM:

La formación de docentes en educación bilingüe intercultural por parte de la Universidad de San Carlos de Guatemala, a través de la Escuela de Formación de Profesores de Enseñanza Media, es una deuda pendiente hacia los pueblos indígenas, es una responsabilidad como Universidad para dar respuesta a las necesidades educativas de los niños, niñas y jóvenes en contextos culturalmente diversos y que han añorado recibir una educación en su propio idioma, cultura, partiendo de sus propios saberes ancestrales para tener una educación propia y altamente pertinente. Por eso, la EFPEM tomó la decisión de implementar la formación de profesionales en educación bilingüe intercultural. ${ }^{34}$

La importancia del aporte de la EFPEM en materia de formación docente hacia el Sistema Educativo se encuentra en graduar profesionales con alto desempeño y conocedores de la realidad sociocultural de Guatemala, enmarcados en los objetivos ${ }^{35}$ institucionales siguientes:

a. Formar profesores para las diferentes materias y disciplinas del plan oficial del Sistema Educativo Nacional.

b. Organizar y ejecutar programas de profesionalización para el personal docente en servicio que no cuentan con especialización en la enseñanza de las materias bajo su responsabilidad.

c. Promover la creación de programas de formación docente de acuerdo con las demandas y necesidades existentes en el Sistema Educativo Nacional.

d. Desarrollar la investigación científica en el marco de la educación nacional para contribuir a la solución de problemas educativos nacionales.

33 "Informe de ejecución académica", EFPEM-USAC (Guatemala: 2017).

34 Entrevista a Danilo López Pérez, Guatemala, 10 de enero de 2019.

35 "Normativo de funcionamiento de EFPEM" (Guatemala: 2015). 


\section{Análisis del desarrollo y desafíos en la formación docente bilingüe intercultural}

\section{Una mirada desde los actores}

Para conocer el desarrollo de los diferentes procesos de la formación docente en Educación Bilingüe Intercultural desde los propios beneficiarios, estudiantes y egresados, así como de las autoridades educativas de la Escuela de Formación de Profesores de Enseñanza Media (EFPEM), se realizaron entrevistas personales y se aplicó un cuestionario con preguntas abiertas a estudiantes, egresados y autoridades educativas, así como la organización de un grupo focal para obtener la información sobre diferentes aspectos del tema de investigación.

Los estudiantes y egresados sujetos de investigación provenían de diferentes grupos étnicos, entre los cuales se pueden mencionar Achí, Akateco, Chuj, Ixil, Kaqchikel, Mam, K'iche', Popti, Poqomchi', Q'anjob'al, Q'eqchi', Tektiteko, Tz'utujil, Uspanteko, todos pertenecientes al pueblo Maya.

Los resultados obtenidos en los diferentes aspectos investigados proporcionan importante información respecto a:

i. Impresión que tienen del desarrollo de la formación docente en educación bilingüe intercultural. El $36 \%$ de los investigados lo catalogan como bueno, el $28 \%$ muy bueno, el $18 \%$ como excelente, el $18 \%$ cree que se puede mejorar tomando en cuenta elementos técnicos, administrativos y logísticos.

ii. El grado de incidencia que han experimentado en cuanto a la formación universitaria en EBI y la aplicación en su área de trabajo. Los investigados dieron a conocer las respuestas siguientes:

- Preparación para el manejo de procesos metodológicos y curriculares para facilitar los aprendizajes de los estudiantes en su propio idioma.

- Se han desarrollado procesos innovadores en la aplicación de la EBI con niños, niñas y jóvenes, según el nivel académico que se atiende y necesidades educativas detectadas.

- Participación en comisiones de calidad con mayor comprensión e interés para compartir experiencias con otros colegas docentes.

- Se necesita fortalecer más el ámbito de formación para el nivel medio, ciclo básico y diversificado, dado que el Ministerio de Educación no ha profundizado el abordaje de la Educación Bilingüe Intercultural.

- Aun cuando se necesita aprender más de cómo hacer para mejorar la Educación Bilingüe Intercultural, se ha aprovechado para incidir en el aula y por consiguiente fortalecer la identidad cultural, étnica y lingüística de los estudiantes, según contexto de trabajo.

iii. A partir de la experiencia en la formación docente en la EFPEM-USAC, ¿cuáles podrían ser los retos y desafíos que se deben tomar en cuenta para proponer respuestas en la mejora de los diferentes procesos académicos en la formación docente en educación bilingüe intercultural? Las respuestas más contundentes fueron las siguientes: 
- Establecer un modelo de formación con asesoría pedagógica.

- Definir un perfil de egreso del docente en Educación Bilingüe Intercultural, que asegure un desempeño efectivo en las prácticas de aula y de desarrollo comunitario, particularmente en contextos de diversidad cultural.

- Fortalecimiento del idioma materno.

- Que el proceso de formación se edifique desde los saberes ancestrales y las prácticas comunitarias.

- Desarrollar la educación propia ${ }^{36}$ como fundamento a la formación docente.

- Mejorar el diseño curricular desde un modelo de educación bilingüe intercultural que fortalezca la identidad cultural, el fortalecimiento y desarrollo idiomático para el aprendizaje en dos idiomas.

- Mejorar la formación de los formadores de formadores en congruencia con la Educación Bilingüe Intercultural.

- Incrementar las oportunidades de ingreso a la universidad para estudiantes indígenas, no solo Mayas, sino también Xincas y Garífunas.

A partir de organizar las respuestas proporcionadas por estudiantes, egresados, catedráticos y autoridades educativas, se puede observar que existen grandes desafíos para avanzar y mejorar la formación de docentes en EBI desde el nivel superior.

\section{Desafíos para la formación docente en EBI a nivel superior}

Partiendo de las respuestas de los sujetos investigados, se abordan cuatro desafíos puntuales para mejorar la formación docente en Educación Bilingüe Intercultural, aporte que pretende contribuir a efectivizar la preparación y desempeño de los futuros profesionales y primordialmente que cumplan con responsabilidad y liderazgo la función docente, desarrollando una educación con pertinencia cultural, étnica y lingüística en el país.

Es importante señalar que uno de los factores que contribuyen a la calidad educativa es el desempeño del docente, y particularmente de aquellos docentes asignados a población escolar indígena y que requieren de una comprensión de su ámbito geográfico, social y cultural para asegurar aprendizajes pertinentes. Promover una educación bilingüe intercultural requiere profundizar la formación de docentes y para el caso de Guatemala

[...] se necesitan de docentes que puedan desempeñarse en contextos interculturales, multiculturales, multilingües y multiétnicos para que la labor docente viabilice los aprendizajes de los estudiantes según sus necesidades, intereses y expectativas de formación y viabilice una educación con calidad. ${ }^{37}$

\footnotetext{
36 Daniel Mato. Instituciones interculturales de Educación Superior en América latina. Procesos de Construcción, logros, innovaciones y desafíos. (Venezuela: IESALC-UNESCO, 2009), 43.

37 Oscar Hugo López Rivas, “Competencias docentes para contextos de diversidad cultural, étnica y lingüística”, Proyecto USAID/ Reforma Educativa en el Aula y Escuela de Formación de Profesores de Enseñanza Media de la Universidad de San Carlos de Guatemala (Guatemala: USAC), 16.
} 
La EFPEM ha avanzado en el desarrollo de las diferentes carreras que apuntan a formar profesionales que contribuyan en el fomento y práctica de la Educación Bilingüe Intercultural, es evidente que estos procesos pueden mejorarse desde el ámbito de técnico, académico, de desarrollo curricular, entre otros aspectos que la EFPEM-USAC debe mejorar la formación de sus futuros profesionales, especialmente de los profesionales en educación bilingüe intercultural.

Crear las mejores condiciones para la formación de docentes en EBI, significa para la EFPEM-USAC enfrentar los desafíos que presentan los diferentes procesos y ámbitos de acción; significa profundizar en los cambios que promuevan la calidad de desempeño de los futuros profesionales. Es por esta razón que a la luz de lo manifestado por el grupo de sujetos que intervinieron en la investigación, se presentan algunos desafíos que a consideración del autor se deben considerar:

\section{Rediseño del currículo de la formación docente en EBI}

El análisis y discusión del currículo actual de la formación docente en EBI son importantes para desarrollar una mejor preparación de los estudiantes en las diferentes carreras que se ofrecen en la EFPEM. Es necesario considerar elementos claves que todo profesional de la EBI debe conocer y manejar oportunamente.

[...] considera que en el factor curricular, se puede observar que es mejorable la relación de los cursos y procesos como un seguimiento sistemático a la formación en EBI, considerando que desde la etapa del profesorado, pasando por la licenciatura y finalmente la maestría deben existir hilos de conducción que favorezcan la formación de los futuros profesionales de manera integrada y sólida para tener una incidencia en el desarrollo de las habilidades y en el campo laboral. ${ }^{38}$

Por otra parte, se deben despejar las dudas en cuanto a la utilización del concepto bilingüe intercultural para el manejo apropiado entre los formadores de formadores y los futuros profesionales, considerando que en "Guatemala el concepto vigente es el de Educación Bilingüe Intercultural, EBI. El énfasis en lo bilingüe obedece a la necesidad de recuperar, fortalecer y desarrollar los idiomas mayas, xincas y garífuna" ${ }^{39}$.

Desde esta perspectiva, también lo intercultural se debe profundizar para el abordaje claro y conciso en el marco de las relaciones interculturales de convivencia, reconocimiento del otro y del enriquecimiento y aprendizaje entre grupos culturalmente diversos; sobre el particular, es importante tomar en cuenta que

38 Pedro Us y Obispo Rosales, ¿Hacia dónde va la Educación Bilingüe Intercultural, EBI, o Intercultural Bilingüe. EIB, en Mesoamérica? (Guatemala: Editorial Cholsamaj, 2014).

39 Ibíd., 39. 
[...] la interculturalidad, como proceso educativo, responde a la búsqueda del reconocimiento de las diferentes identidades sociales y culturales, a la consideración de que hay diversas formas de ver y de percibir el mundo y a la renovación de las prácticas pedagógicas que conduzcan a la inclusión de nuevos saberes y de nuevas prácticas culturales. ${ }^{40}$

Lo importante en estos procesos de formación no solo es el fortalecimiento del idioma materno como un elemento de la identidad cultural, sino que se fomente y practique desde la formación profesional la educación intercultural como un mecanismo efectivo para contribuir en la consolidación de una sociedad incluyente y respetuosa de la diversidad cultural.

Dentro del marco del rediseño curricular para fortalecer la formación docente en EBI, también se deben incorporar aspectos relacionados con los elementos de las culturas y los idiomas indígenas, lo cual fundamenta que la diversidad cultural y lingüística sean la base de una pedagogía intercultural ${ }^{41}$. Así también se deben considerar los saberes de los pueblos, el conocimiento Maya, la oralidad, como mecanismos de transmisión de conocimientos y prácticas ancestrales, diálogo y ciudadanía intercultural, las costumbres, el fortalecimiento de la identidad cultural, la cosmogonía, entendiéndose como la forma de concebir la vida, el mundo y la naturaleza y la educación propia ${ }^{42}$.

\section{Formación en competencias para contextos de diversidad cultural, étnica y lingüística ${ }^{43}$}

Uno de los factores asociados a la calidad educativa es la formación y desempeño del docente, profesional que incide en la formación y destino de los niños y jóvenes "permitiéndoles ofrecer servicios educativos de calidad que faciliten desde el aula, el aprendizaje y desarrollo de competencias para la vida" ${ }^{44}$.

Un profesional de la educación bilingüe intercultural altamente formado debe egresar con las habilidades docentes que le permitan realizar una práctica y orientación pedagógicas adecuadas a las necesidades e intereses de la población estudiantil y de la comunidad como fuente de conocimientos, valores y cultura; debe poseer las competencias fundamentales para hacer efectivo el aprendizaje en contextos de población indígena, es decir, una formación que permita el desa-

40 Norman Estupiñán Quiñones y Nubia Agudelo Cely, "Identidad cultural y educación en Paulo Freire: reflexiones en torno a estos conceptos", Revista historia de la educación latinoamericana, n. ${ }^{\circ} 10$ (2012) https://revistas.uptc.edu.co/index.php/historia educacion_latinamerican/article/view/1484 (8/6/2019).

41 Celso Cuxil Sotz, ¿Hacia dónde va la educación bilingüe intercultural, EBI, o intercultural bilingüe, EIB, en Mesoamérica? (Guatemala: Editorial Cholsamaj, 2014), 54.

42 Consejo Nacional de Educación Maya (CNEM), "Educación propia: Pueblos Maya, Xinka y Garífuna. Lineamientos de construcción de políticas y de diseño y aplicación curricular" (Guatemala: 2013).

43 López Rivas, "Competencias docentes".

44 Edda Fabián, María de los Ángeles Zavala Bonilla y Gabriela Castro de Burbano, "Principales desafíos de la educación en Guatemala”, Revista Asies, n. ${ }^{\circ} 2$ (2017), 25. 
rrollo "de habilidades, conocimientos y actitudes que inspiren a sus estudiantes a aprender para la vida, desde su contexto y cultura" ${ }^{45}$.

Para una buena formación docente es necesario considerar aspectos sobresalientes que permitan al nuevo profesional cumplir eficientemente en el campo pedagógico, contextual, sociocultural, cultural y de desarrollo educativo, por lo que es necesario identificar las competencias docentes que debe poseer, especialmente para contextos de diversidad cultural, étnica y lingüística ${ }^{46}$.

\section{Competencias docentes}

a. Compromiso con la equidad, la igualdad y la ética. Corresponden a los valores personales que facilitan su desempeño y la relación adecuada con los demás, no importando la procedencia cultural, étnica y lingüística de las personas.

b. Compromiso con el aprendizaje y el desarrollo integral de los estudiantes, tomando en cuenta su identidad cultural, étnica y lingüística. Se refiere a la adecuada comunicación con los estudiantes y miembros de la comunidad educativa, a la capacidad de enseñar, evaluar y monitorear el aprendizaje y a mantener un clima apropiado para el aprendizaje.

c. Compromiso con su continua actualización en los conocimientos de las disciplinas que enseña, y el arte de enseñar para el desarrollo y formación integral de sus estudiantes. Alude al buen dominio que el docente debe tener de los contenidos de las áreas curriculares que imparte y a la forma como el docente guía el aprendizaje de sus alumnos, según el contexto sociocultural.

d. Compromiso con la calidad en su desempeño docente y crecimiento profesional. Se relaciona con el ejercicio docente y profesional tanto en las actividades escolares como con otros miembros de la comunidad educativa.

El desafío primordial para formar a los futuros docentes es enorme, principalmente para llevar a cabo una educación de calidad para los niños y jóvenes que poseen un idioma materno diferente al español, con saberes propios, con experiencias educativas muy efectivas originadas desde su contexto cultural y étnico y que por muchos años no han tenido respuesta de las instituciones que son responsables de la formación de los futuros profesionales; razón por la cual se hace necesario el análisis y discusión para cumplir con el mandato del derecho a la educación con calidad para todos y todas, cumpliendo con una educación que responda a la caracterización sociolingüística y cultural de la región ${ }^{47}$.

45 Proyecto de Desarrollo Santiago (PRODESSA), “¿Hacia dónde va la educación pública en Guatemala? Calidad educativa y Educación Bilingüe Intercultural”, Boletín n. ${ }^{\circ}, 8$.

46 López Rivas, “Competencias docentes”, 16-24.

47 La caracterización sociolingüística de escuelas en Guatemala es un proceso de identificación geográfica y contextual de los idiomas indígenas para establecer el modelo educativo por desarrollar, organizado por el Ministerio de Educación de Guatemala. 
Oportunidades de ingreso a la universidad para estudiantes indígenas

La formación docente en educación bilingüe intercultural en la EFPEM se ha venido dando a partir del año 2002, con graduaciones en los diferentes niveles educativos; sin embargo, ante las necesidades de atención educativa en contextos de diversidad cultural en Guatemala, se necesita incrementar la cobertura para que más estudiantes indígenas puedan optar por una carrera de esta naturaleza. Promover la incorporación de más estudiantes significa priorizar las políticas de inclusión universitaria de estudiantes, hombres y mujeres, que puedan fortalecer sus conocimientos y experiencias en contextos culturalmente diversos, y además formarse para promover una educación bilingüe intercultural.

Dentro de las propuestas para aumentar la matrícula de estudiantes se pueden mencionar las siguientes:

a. Crear un fondo de becas para estudiantes de poblaciones indígenas de manera permanente, que incluya a jóvenes Mayas, Garífunas y Xincas, de tal forma que se establezcan criterios de selección proporcional según las necesidades de profesionales para la Educación Bilingüe Intercultural.

b. Promover otras fuentes de financiamiento para la incorporación de estudiantes indígenas con organizaciones nacionales e internacionales para que, previo estudio de demanda educativa, se identifiquen las necesidades reales, tomando en cuenta los diferentes grupos étnicos de la región.

c. Determinar nuevas modalidades de formación a través del uso de la tecnología para brindar oportunidades a estudiantes que vivan en lugares lejanos a los centros universitarios y así puedan ser beneficiados para continuar su formación a nivel superior.

\section{La investigación y la formación de formadores}

Promover desde la academia la investigación educativa sobre aspectos que inciden directamente en la mejora de la educación bilingüe intercultural es un factor de éxito en la formación de los formadores que tienen bajo su responsabilidad la preparación de los futuros profesionales de esta área. Es importante viabilizar una línea de acción integrada entre investigación y formador de formadores, considerando que los elementos curriculares, metodológicos, contextuales, entre otros, deben partir del conocimiento pleno de quienes tienen la responsabilidad de ser profesores universitarios.

Los formadores de formadores mejorarán su entrega educativa a partir de los procesos de investigación que deben realizar permanentemente, tomando en cuenta que no es lo mismo formar docentes para contextos de población ladina que para contextos indígenas, razón por la cual la investigación debe ser un elemento de base para la promoción de acciones desde el pleno y real conocimiento del ambiente cultural, étnico y lingüístico de la población estudiantil. 
La responsabilidad institucional de la EFPEM en la formación de los mejores profesionales en educación debe incidir en el desarrollo educativo del país y esto se enmarca en uno de los objetivos de la maestría en Educación Bilingüe Intercultural que actualmente se desarrolla: "Formar profesionales comprometidos y altamente calificados para responder a las necesidades e imperativos de la Educación Bilingüe Intercultural guatemalteca, con vistas al desarrollo de procesos educativos de calidad" 48 .

Es necesario investigar y fortalecer la formación de formadores desde elementos que están íntimamente relacionados con el contexto cultural para que posteriormente se conozcan otros contextos como fuente de enriquecimiento y desarrollo entre culturas. Entre otros procesos se pueden mencionar:

a. Los saberes ancestrales como base para el fomento y enriquecimiento de nuevos conocimientos de otras culturas.

b. Aprendizajes desde el idioma materno, la cultura, cosmovisión, costumbres $\mathrm{y}$ formas de vida.

c. Modelos de Educación Bilingüe Intercultural.

d. Modelos para el aprendizaje desde una segunda o tercera lengua.

e. Cómo se genera la educación propia y el aporte hacia otras culturas.

f. La educación intercultural como un proceso de fortalecimiento de aprendizajes desde otras cultural, del reconocimiento del otro, del respeto y fomento de una convivencia armónica.

g. Ciudadanía intercultural.

h. Caracterización sociolingüística de las diferentes regiones.

Es lógica la vinculación del rediseño curricular y los procesos de investigación y formación de formadores con fundamento en un modelo pedagógico que debe cimentar los postulados de la formación docente en búsqueda de integrar la teoría y la práctica entre los estudiantes, basándose en la investigación pedagógica, desde donde se realiza la docencia y la extensión, en un compromiso con la comunidad regional y nacional para que cumplan las acciones de liderazgo y ostenten la capacidad para participar, desde los valores éticos, en la solución de problemas comunitarios, para construir el país que soñamos, en la utopía de asimilar y aportar en los nuevos retos que nos plantea el siglo XXI ${ }^{49}$.

En la formación docente en EBI que se desarrolla en la EFPEM-USAC, se han realizado varias tareas de investigación por parte de los estudiantes del grado de licenciatura y maestría dentro de los trabajos de tesis, previo a sustentar el examen final de graduación, labor que ha permitido reflexionar y constatar sobre la teoría y práctica de la EBI, profundizando sus conocimientos y experiencias para aportar en el mejoramiento de la educación para contextos multiculturales.

Para visualizar algunos estudios de investigación en los procesos de tesis elaborados por estudiantes, se mencionan los siguientes:

48 EFPEM-USAC, Diseño curricular de Maestría en Educación Bilingüe Intercultural (Guatemala: 2015).

49 Diana Soto Arango, Pascual Mora García y José Rubens Lima Jardilino, Formación de docentes y modelo pedagógico en la Universidad Pedagógica y Tecnológica de Colombia (Tunja: UPTC-Búhos Editores, 2017), 61. 
a. "La formación de los niños maya-hablantes en la Educación Bilingüe Intercultural", evidencia que la EBI es un factor que incide en los aprendizajes de los niños, particularmente cuando se utilizan metodologías contextualizadas y eficientes ${ }^{50}$.

b. "Competencia docente e interculturalidad en el Área de Interculturalidad y Pedagogía de la Diversidad", da a conocer el grado de conocimientos y experiencias de las competencias interculturales que tienen los docentes que laboran en Escuelas Normales bilingües del departamento de San Marcos ${ }^{51}$.

c. "La formación del docente y el aprendizaje bilingüe de los estudiantes", evidenció el bajo nivel de formación de los docentes para propiciar aprendizajes en la modalidad bilingüe en niños y niñas de escuelas primarias, en el municipio de Huehuetenango ${ }^{52}$.

d. "Factores que inciden en el desuso de la indumentaria maya por parte de mujeres universitarias", investigación vinculada a un fenómeno social que afecta a las mujeres indígenas en el desuso de la indumentaria Maya, asociado a razones de discriminación, falta de recursos económicos y a que en la misma universidad no se ha avanzado en los procesos de inclusión y educación para los pueblos indígenas ${ }^{53}$.

Estos trabajos evidencian las líneas de investigación que en materia de Educación Bilingüe Intercultural se ejecutan en la Escuela de Formación de Profesores de Enseñanza Media, EFPEM-USAC, los cuales fortalecen la preparación de los futuros profesionales para promover e implementar una educación más incluyente, intercultural y contextualizada desde los pueblos indígenas.

\section{CONCLUSIÓN}

La formación universitaria de docentes para la atención de la Educación Bilingüe Intercultural requiere dar pasos bien definidos para cambiar las formas tradicionales que por décadas se han venido desarrollando; se necesita dar un impulso con el desarrollo de acciones que cambien las formas de llevar a las aulas de tal manera que el profesional egresado de la universidad pueda realizar su labor docente con conocimiento y causa de los nuevos enfoques y modelos que aseguren una educación con calidad y pertinencia cultural étnica y lingüística.

La Universidad de San Carlos de Guatemala, por medio de la Escuela de Formación de Profesores de Enseñanza Media (EFPEM) lidera la formación de docentes en todos los niveles educativos en diferentes modalidades de entrega;

50 Juan Ordóñez Domingo, "La formación de los niños maya-hablantes en la Educación Bilingüe Intercultural" (tesis de pregrado, Universidad de San Carlos de Guatemala, 2016), 113.

51 Bayron Baldomero Ramírez Témaj, "Competencia docente e interculturalidad en el Área de Interculturalidad y Pedagogía de la Diversidad” (tesis de pregrado, Universidad de San Carlos de Guatemala, 2013), 129.

52 Yasmina Amable Granados Castillo, "La formación del docente y el aprendizaje bilingüe de los estudiantes" (tesis de pregrado, Universidad de San Carlos de Guatemala, 2016), 102.

53 Ana Paola María Perén Cutzal, "Factores que inciden en el desuso de la indumentaria maya por parte de mujeres universitarias" (tesis de pregrado en la Universidad de San Carlos de Guatemala, 2018), 69. 
dentro de sus alcances se puede visualizar la formación de los futuros profesionales en educación bilingüe intercultural, formación que ha incidido en el desarrollo educativo de los pueblos indígenas.

Aunque son numerosos los retos y desafíos que se tienen para avanzar en fortalecer la educación con pertinencia cultural, étnica y lingüística de Guatemala, con el esfuerzo de la EFPEM se promueven las oportunidades de formación para la población indígena que dentro de sus intereses desean un mejoramiento en el tema curricular, en procesos que desarrollen las competencias docentes para contextos de diversidad cultural, étnica y lingüística, incrementen la cobertura para estudiantes y en que los formadores tengan el pleno conocimiento, experiencia y responsabilidad para la formación de los futuros profesionales en la EBI.

Es necesario bajo estos requerimientos estudiantiles, trabajar en el rediseño curricular que tome en cuenta aspectos como los saberes ancestrales, la cosmovisión indígena, los valores, costumbres, formas de vida, educación propia, aprendizajes desde su idioma materno, desde la convivencia de los cuatro pueblos que habitan el territorio y que estos sirvan de base para aprender del otro como base para el desarrollo personal y comunitario.

Para desarrollar acciones puntuales en la formación de docentes en EBI, esta debe contener características fundamentadas en la diversidad cultural y por consiguiente promover una formación que promuevan competencias docentes para contextos de diversidad cultural, étnica y lingüísticas de Guatemala. Cabe mencionar que para este caso, "La labor docente en áreas con predominancia indígena, debe tener además de las competencias básicas docentes, otros conocimientos, habilidades, destrezas, actitudes y valores que le permitan generar su trabajo con fundamento a las exigencias y necesidades de esa población" ${ }^{\prime 2}$. Este es un elemento que toda institución educativa de nivel superior debe tomar en cuenta para que efectivamente cumpla con las necesidades y demandas educativas del país.

Por otra parte, aumentar la cobertura de estudiantes indígenas que se desempeñarán como docentes en Educación Bilingüe Intercultural es una necesidad latente en la educación superior, si se parte de la demanda educativa existente en el país en estos contextos; estos procesos deben ir acompañados con políticas que promuevan el apoyo a estudiantes a través de becas universitarias con participación de instituciones nacionales e internacionales y la implementación de modalidades de entrega educativa para áreas alejadas a los centros universitarios.

Finalmente, es importante generar procesos de investigación educativa con participación de los formadores de formadores, relacionadas a la EBI para que los resultados tengan el análisis y discusión correspondientes para la incorporación en la formación docente y, principalmente, que sirvan de base para la actualización y contextualización de los futuros profesionales universitarios.

54 López Rivas, “Competencias docentes”, 16. 


\section{FUENTES}

Entrevista a López Pérez, Danilo, director de la Escuela de Formación de Profesores de Enseñanza Media. Guatemala, 10 de enero de 2019.

\section{REFERENCIAS}

Consejo Nacional de Educación Maya (CNEM). "Educación propia: Pueblos Maya, Xinka y Garífuna. Lineamientos de construcción de políticas, y de diseño y aplicación curricular". Guatemala, 2013.

Cojtí Cuxil, Demetrio. Glosario sobre diversidad étnica y cultural de Guatemala. Guatemala: Editorial Cholsamaj, 2010.

Coyote Guitzol, Víctor. "Educación Bilingüe Intercultural”. Revista Del blog a la Revista, año 2, Edición 6, (2018), 15.

Domínguez Garrido, María, Adiela Ruiz Cabezas y Antonio Medina Rivilla. “Experiencias docentes y su proyección en la identidad profesional: El caso de las maestras de Santa Marta y su entorno". Revista historia de la educación latinoamericana 19, n. ${ }^{\circ} 29,111-34$. https://doi. org/10.19053/01227238.7555 (18/8/2019)

EFPEM. Informe de labores. Dirección EFPEM (2018).

EFPEM-USAC. Diseño curricular de maestría en Educación Bilingüe Intercultural (2015).

Estupiñán Quiñones, Norman y Nubia Agudelo Cely. "Identidad cultural y educación en Paulo Freire. Reflexiones en torno a estos conceptos". Revista historia de la educación latinoamerica$n a, \mathrm{n} .^{\mathrm{o}} 10$ (2012). https://revistas.uptc.edu.co/index.php/historia_educacion_latinamerican/ article/view/1484 (09/6/2019).

Fabián, Edda, María de los Ángeles Zavala Bonilla y Gabriela Castro de Búrbano. “Principales desafíos de la educación en Guatemala". Revista Asíes, n. ${ }^{\circ} 2$ (2017).

González Orellana. Carlos. Historia de la Educación en Guatemala. Guatemala: Editorial Universitaria, Universidad de San Carlos de Guatemala, 2011.

Granados Castillo, Yasmina Amable. "La formación del docente y el aprendizaje bilingüe de los estudiantes". Tesis de pregrado. Universidad de San Carlos de Guatemala, 2016.

Historia de la ENRO, Sololá. Documento inédito de la Dirección del establecimiento educativo (2018).

Lafuente Guantes, María. "Educación intercultural y formación del profesorado". Revista historia de la educación latinoamericana 19, n. ${ }^{\circ} 29$ (2017). https://doi.org/10.19053/01227238.7554 $(18 / 8 / 2019)$.

López Rivas, Oscar Hugo. “Competencias docentes para contextos de diversidad cultural, étnica y lingüística". Proyecto USAID/Reforma Educativa en el Aula y Escuela de Formación de Profesores de Enseñanza Media de la Universidad de San Carlos de Guatemala (2011).

López Rivas, Oscar Hugo y José Enrique Cortez Sic. Las Escuelas Normales en Guatemala, Origen y desarrollo, crisis y situación actual. Guatemala: UPTC, 2016.

López Rivas, Oscar Hugo. Bases para el Diseño del Sistema Nacional de Formación Docente en Guatemala. Guatemala: Ediciones USAC, 2013.

Mato, Daniel. (Coordinador) Instituciones interculturales de Educación Superior en América latina. Procesos de Construcción, logros, innovaciones y desafíos: IESALC-UNESCO, 2009.

Ministerio de Educación de Guatemala. Acuerdo Marco entre el Ministerio de Educación y la Universidad de San Carlos de Guatemala (2013).

Ministerio de Educación de Guatemala. Estrategia para una educación de calidad para la niñez y juventud guatemalteca. Guatemala: Editorial Tipografía Nacional de Guatemala, 2013.

Ministerio de Educación de Guatemala. Informe de implementación de la FID por la Dirección General de Gestión de la Calidad Educativa (DIGECADE) y la Dirección General de Educación Bilingüe Intercultural (DIGEBI) (2019). 
Ministerio de Educación de Guatemala. Precongresos y Congresos Nacionales. Educación bilingüe Intercultural. Consejo Nacional de Educación. Guatemala (2016).

Ministerio de Educación de Guatemala, Dirección General de Educación Bilingüe Intercultural. La Educación Bilingüe Intercultural en el Sistema Educativo Nacional. Líneas generales (2013).

Ministerio de Educación de Guatemala, Dirección General de Educación Bilingüe Intercultural. La caracterización sociolingüística de escuelas en Guatemala es un proceso de identificación de la ubicación y utilización de los idiomas indígenas para establecer el modelo educativo a desarrollar (2013).

Morales, Mario Roberto. Estética y política de la interculturalidad. Guatemala: Ediciones Superiores, 2017.

Mugrabi, Edivanda. Teoría y práctica de la pedagogía del texto. Guatemala: USAC-Enfants du monde, 2019.

Ordóñez Domingo, Juan. “La formación de los niños maya-hablantes en la Educación Bilingüe Intercultural". Tesis de pregrado. Universidad de San Carlos de Guatemala, 2016.

Peláez Almengor, Óscar. La Escuela de Formación de Profesores de Enseñanza Media EFPEM. ¿Un poema pedagógico? Guatemala: CEUR, 2014.

Perén Cutzal, Ana Paola María. "Factores que inciden en el desuso de la indumentaria maya por parte de mujeres universitarias". Tesis de pregrado. Universidad de San Carlos de Guatemala, 2018.

Proyecto de Desarrollo Santiago (PRODESSA). “¿Hacia dónde va la educación pública en Guatemala? Calidad educativa y Educación Bilingüe Intercultural”. Boletín n. ${ }^{\circ} 2,2014$.

Ramírez Témaj, Bayron Baldomero. “Competencia docente e interculturalidad en el Área de Interculturalidad y Pedagogía de la Diversidad". Tesis de pregrado. Universidad de San Carlos de Guatemala, 2013.

Secretaría académica EFPEM. Informe anual de acciones académicas de EFPEM. Guatemala (2017).

Soto Arango, Diana, Pascual Mora García y José Rubens Lima Jardilino. "Formación de docentes y modelo pedagógico en la Universidad Pedagógica y Tecnológica de Colombia". Revista historia de la educación latinoamericana, 19, n. ${ }^{\circ}$ 29. https://doi.org/10.19053/01227238.7552.

Universidad Rafael Landívar. Reescrituras de la educación pública desde Centroamérica. Guatemala: Serviprensa, 2016.

Us, Pedro y Obispo Rosales Yax. ¿Hacia dónde va la Educación Bilingüe Intercultural, EBI, o Intercultural Bilingüe. EIB, en Mesoamérica? Guatemala: Editorial Cholsamaj, 2014.

Velásquez, Jorge Raymundo. Educación bilingüe intercultural o educación intercultural bilingüe. Guatemala: Universidad Rafael Landívar-Cara Parens, 2015.

Cómo citar:

Cortez Sic, José Enrique. "Avances y desafíos en la formación universitaria de docentes en Educación Bilingüe Intercultural".

Revista Historia de la Educación Latinoamericana. Vol. 21 No. 33 (2019): 245-273

DOI: https://doi.org/10.19053/01227238.9909

(c) (i) @ (9) Esta obra está bajo una licencia Creative Commons.

Reconocimiento-No Comercial-Sin Obra Derivada 2.5 Colombia. 